\title{
UM OLHAR JURÍDICO-ANTROPOLÓGICO SOBRE OS EMPREENDIMENTOS ECONÔMICOS SOLIDÁRIOS NÃO FORMALIZADOS NA BAHIA: ORGANIZAÇÕES "INVISÍVEIS"?
}

\author{
A LEGAL ANTHROPOLOGICAL GAZE ON SOLIDARITY ENTERPRISES \\ NOT FORMALIZED IN BAHIA: ORGANIZATIONS "INVISIBLE"?
}

Gabriela da Luz Dias*

RESUMO: Propomos investigar neste artigo as relações informais estabelecidas pelos sujeitos da economia solidária, em especial, aquelas oriundas dos seus principais atores - os empreendimentos econômicos solidários. Abordaremos também uma grande dificuldade enfrentada na sociedade hodierna, refletida na tentativa de conciliar a existência fática destes atores com um dos princípios basilares do Estado democrático de direito: a segurança jurídica. Para alcançar esse fim, utilizaremos uma perspectiva jurídico-antropológica cujo enfoque pretenderá desvelar os modelos jurídicos organizacionais existentes e regularmente adotados, a posição do empreendimento econômico solidário dentro desta classificação, as diferentes nuances que permeiam estes modelos e a dinâmica construída no interior destas organizações.

PALAVRAS-CHAVE: Economia solidária. Empreendimento de economia solidária. Organização informal.

ABSTRACT: This article we propose to investigate the relationships established by the subjects of the informal economy, into masters of, those originating from its main actors - the sympathetic enterprises. Also discuss a major difficulty faced by society reflected in an attempt to reconcile the dull existence of these actors with the basic principles of the democratic sate of law: Legal security. To reach this end, we use a perspective Legal anthropological whose focus had intended to reveal the organizational models juridical existence and regularly adopted the position of Economic solidarity development within this classification, the different nuances that permeate these models and dynamic build inside these organizations.

KEYWORDS: Solidarity economy. Development of solidarity economy. Informal organizations.

* Mestranda em Ciências Sociais pela Universidade Federal do Recôncavo da Bahia: Cultura, desigualdades e desenvolvimento. Bolsista CAPES. Advogada. E-mail: gabriela_fd@yahoo.com.br 


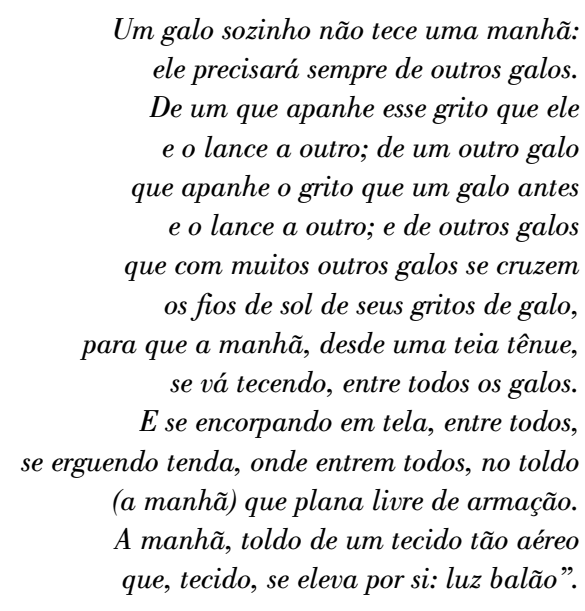

(João Cabral de Melo Neto, Tecendo a manhã)

\section{INTRODUÇÃ̃O}

O motivo que ensejou a elaboração do presente artigo foi a necessidade do estabelecimento de uma conexão entre o olhar jurídico e o antropológico no momento de analisar os empreendimentos de economia solidária. Estas áreas, aparentemente distantes, são capazes de se imbricar quando tratamos deste objeto, conforme poderemos ver a seguir.

Para o antropólogo Geertz (2009), o direito e a etnografia "são artesanatos locais: funcionam à luz do saber local". Nesse sentido, ainda afirma:

Sejam quais forem as outras características que a antropologia e a jurisprudência possam ter em comum - como, por exemplo, uma linguagem erudita meio incompreensível e uma certa aura de fantasia - ambos se entregam à tarefa artesanal de descobrir princípios gerais em fatos paroquiais.

É cediço que todas as sociedades conhecem o Direito. No entanto, enquanto as "tradicionais" relativizam seu papel, as sociedades "ocidentais modernas" o enfatizam. Em toda sociedade existe um corpo definidor de regras, normas e (ou) códigos, capaz de prescrever direitos e deveres. O direito, portanto, não é uma prerrogativa das sociedades modernas: todas as sociedades o conhecem, porém o fazem de formas diferentes, a ponto de algumas sequer utilizarem esta denominação (GEERTZ, 2009).

Geertz propõe um contato novo entre esses dois saberes a fim de que haja uma consciência maior e mais precisa do que a outra disciplina significa, mediante:

(...) uma busca de temas específicos de análise que, mesmo apresentando-se em formatos diferentes, e sendo tratados de maneiras distintas, encontram-se no caminho das duas disciplinas (...) um ir e vir hermenêutico entre os dois campos, olhando primeiramente em uma direção, depois na outra, a fim de formular as questões morais, políticas e intelectuais que são importantes para ambos (p. 253). 
O grandioso desafio para estas duas áreas versa a respeito da possibilidade de relacionar o vivenciado com o concebido - a chance de atrelar o fato à lei. Essa interseção entre o teórico e o empírico apresenta um caráter ficcional que permite tanto os juristas quanto os antropólogos encontrar significado não no que de fato ocorreu, mas na interpretação daquilo que se fez do que aconteceu.

No que tange à elaboração do presente artigo, a Antropologia nos ajudará a entender a dinâmica das organizações e sua real significação. Será também apropriada para elucidar a motivação existente nestes sujeitos para organizarem-se como coletivo. Já o Direito irá esclarecer o conflito firmado entre a existência material dos empreendimentos econômicos solidários informais e o Estado democrático de direito, principalmente no que se refere ao respeito ao princípio de segurança jurídica.

Dessa maneira, a procura por significado faz com que a antropologia e o direito dialoguem não como uma mera tentativa de unir estas duas áreas. Não se trata de nulificar ou ofuscar as singularidades de cada campo, mas, segundo Geertz (2009), versa a respeito da possibilidade de, ainda que de maneiras distintas, um mesmo tema seja analisado pelos dois campos, como um ponto de intersecção entre ambos.

\section{BREVE RETROSPECTIVA HISTÓRICA DO SURGIMENTO DA EXPRESSÃO "ECONOMIA SOLIDÁRIA"}

A Economia Solidária é um movimento novo, surgido no Brasil na década de 1990. Para o professor Paul Singer, as práticas econômico-solidárias surgiram anos depois do advento do capitalismo industrial, em resposta às dificuldades vividas pelos trabalhadores artesãos, provocadas pela conhecida substituição homem pela máquina. (SINGER, 2002, p. 24).

Ela encontra-se atrelada ao surgimento do cooperativismo - movimento nascido em razão da exploração do trabalho, mediante a luta do proletariado em busca de melhores condições de trabalho e dignos salários.

No momento do surgimento desta "outra economia", atualmente conhecida como economia solidária, nasceram movimentos capazes de promover a ajuda mútua e a luta por melhores condições e foram, à época, denominadas de cooperativas operárias.

Outro marco histórico no surgimento do cooperativismo (e consequentemente deste novo modelo econômico) foi o nascimento da famosa cooperativa de consumo em Rochdale, responsável pela propagação do cooperativismo na Europa em meados do século XIX, onde 28 tecelões, em razão das condições de dificuldade e penúria que viviam, se uniram para criar uma organização capaz de atender a sua maior necessidade, qual seja, comprar insumos de primeira necessidade. Essa cooperativa, tida por muitos como pioneira, foi inclusive responsável por difundir na Europa os primeiros princípios do cooperativismo, e nela se via presente forte preocupação com a cooperação, a ajuda mútua, a democracia e a equidade. 
As teorias cooperativistas tomam lugar de destaque na discussão acerca das formas de superação da dicotomia capital-trabalho (SINGER, 2003, GAIGER, 2004), embora não seja o único viés tomado no que diz respeito à investigação de seu papel na sociedade. Há ainda o modelo cooperativo apresentado por Lima (2002) e por outros doutrinadores, de onde se observa a possibilidade de avistar as cooperativas sob outra óptica.

Lima trata das cooperativas simuladas cujo exclusivo intuito é flexibilizar e precarizar as relações de trabalho dos obreiros. Para esse autor, o movimento cooperativista não se limitaria a uma resposta ao desemprego, mas sobretudo como forma alternativa e perversa de produção.

Impende ressaltar, que em que pese seja importante reconhecer a existência das falsas cooperativas, não trataremos delas neste trabalho, já que não é este o objetivo. Trataremos de agora em diante, daquelas que são capazes de inspirar-se nos valores de democracia participativa, equidade e solidariedade.

De acordo com Mance, o conceito de Economia Solidária é ainda mais abrangente, abarcando não somente a possibilidade geradora de trabalho, mas também a vertente responsável por promover a colaboração solidária capaz de garantir harmonia e bemviver dos seus sujeitos:

(...) ao considerarmos a colaboração solidária como um trabalho e consumo compartilhados cujo vínculo recíproco entre as pessoas advém, primeiramente, de um sentido moral de coresponsabilidade pelo bem-viver de todos e de cada um em particular, buscando ampliar-se o máximo possível o exercício concreto da liberdade pessoal e pública, introduzimos no cerne desta definição o exercício humano da liberdade (...) (MANCE, 1999, p.178).

Observe que havia nesta época, portanto, o intuito de substituir os conceitos de "competitividade", próprios da sociedade industrial pelos de "solidariedade", mediante o respeito às máximas de autogestão, cooperação e valorização do trabalho humano.

Importante notar a inconsistência presente na utilização do vocábulo "outra economia" ou "economia da solidariedade" para expressar o surgimento desse acontecimento, tendo em vista que, em verdade, se tratava de um reaparecimento de valores já existentes e presentes em várias comunidades ditas primitivas, em que grupos se organizavam para coletivamente caçar, comer e se relacionar. O sentimento de solidariedade é tão antigo quanto à humanidade. Assim, da mesma forma que no modelo em destaque, em muitas comunidades antigas (e até mesmo em algumas atualmente existentes) observou-se o entrelaçamento da dimensão econômica com outras dimensões sociais, política e culturais.

A partir desse exame, um questionamento pode ser provocado: o que poderia ter sido capaz de provocar a emersão deste fenômeno na sociedade contemporânea?

Conforme dito, inúmeras justificativas são baseadas na crise econômica vivida, fortemente marcada pela disparidade provocada pelo modo de produção capitalista. 
Em resposta, como não se podia contar com o Estado para satisfazer suas necessidades, formas especiais de organização começaram a germinar.

Esse novo modelo, exatamente por perceber as limitações oriundas do sistema vigente, procurou imbricar sua necessidade de sobrevivência e, por conseguinte de geração de trabalho e renda a um bem maior, coletivo, capaz de beneficiar tanto os sujeitos que fazem parte da organização quanto aqueles que não fazem parte dela. Nesta entidade, a necessidade econômica não é um fim em si mesmo, tendo em vista que por meio dela se estabelece toda uma dinâmica de reciprocidade.

\section{OS EMPREENDIMENTOS ECONÔMICOS SOLIDÁRIOS}

Numerosos são os conceitos hoje apresentados para descrever o que sejam empreendimentos econômicos solidários. Uma perfunctória conceituação afirmaria que se trata de um dos atores do movimento de economia solidária. Entretanto, quando partimos para as definições mais substanciais, encontramos definições diversas, que poderão variar a partir da formação do pesquisador. Economistas enfatizarão a capacidade geradora de trabalho e renda da organização, administradores ressaltarão sua capacidade de autogerência, advogados poderão se limitar a tratar dos seus modelos jurídico-organizacionais.

O documento base da II Conferência Nacional de Economia Solidária (2010) relaciona as características necessárias para reconhecer um empreendimento econômico solidário, a saber:

(1) ser uma organização coletiva, singular ou complexa, cujos participantes ou sócios (as) são trabalhadores(as) do meio urbano ou rural; (2) realizar atividades de natureza econômica, socioambiental e cultural que devem ser as razões primordiais da existência da organização; (3) ser uma organização autogestionária, cujos participantes ou sócios exerçam coletivamente a gestão das atividades econômicas e a decisão sobre a partilha dos seus resultados, através da administração transparente e democrática, soberania da assembléia e singularidade de voto dos sócios cumprindo o seu estatuto ou regimento interno; (4) ser uma organização permanente, considerando tanto os empreendimentos que estão em funcionamento quanto aqueles que estão em processo de implantação, desde que o grupo esteja constituído e as atividades econômicas definidas.

Na tentativa de nos ater a uma perspectiva jurídico-antropológica, observamos que o empreendimento econômico solidário, independente de seu modelo jurídicoorganizacional, é uma entidade coletiva capaz de promover a interação dos seus indivíduos e o fortalecimento do grupo mediante a prática de atividade produtiva, responsável por gerar renda e robustecer sua identidade.

Muitas vezes, os empreendimentos econômicos solidários unem sujeitos sociais não hegemônicos, sendo que a preocupação com a geração de trabalho e renda emerge como parte do processo emancipatório dos grupos. Nesses casos se tem intensa 
preocupação em conservar a identidade, a diversidade e valorizar o saber local. Muitas dessas organizações são formadas por povos tradicionais quilombolas, indígenas, fundos de pasto, marisqueiras e pescadores ou por grupos promotores da igualdade de gênero e étnicos. Nesses exemplos, o retorno econômico não é o fim em si mesmo, tendo em vista que seus valores baseiam-se também na conservação da identidade, na manutenção da sua história e resistência pela permanência da tradição da comunidade ou na luta pela igualdade.

No que tange à Constituição legal, atualmente muitos grupos firmam-se como associações, caracterizados pela união de pessoas que se organizam para fins não econômicos. As associações, segundo a legislação vigente, podem ter fins culturais, científico, de assistência, sociais de qualquer espécie, além de outros, desde que não econômicos.

Outros grupos organizam-se como cooperativa, organização marcada pela união de pessoas com objetivo de atingir proveito comum, exercendo atividade econômica não lucrativa.

Segundo o Sistema Nacional de Informações em Economia Solidária - SIES, os Empreendimentos de Economia Solidária têm natureza heterogênea, de modo a se apresentar como associações, cooperativas, sociedades em comum (antigas sociedades informais e de fato) ou outras formas societárias.

Muitas organizações se autodenominam "associações" ou "cooperativas", entretanto, em verdade, não possuem nenhum tipo de registro, permanecendo em um campo nuvioso, como informais e abarcadas por características existentes dos dois modelos jurídico-organizacionais acima citados. A maioria dessas organizações mescla os conceitos acima tratados: produzem coletivamente como as cooperativas e promovem a ajuda mútua como as associações.

A associação brasileira de organizações não governamentais - Abong, em artigo ${ }^{1}$ sobre "proposição de princípios que orientem a formulação de um marco regulatório do acesso, uso e prestação de contas de recursos públicos por entidades sem fins lucrativos no Brasil", apresenta um rol de proposições com objetivo de avançar nas discussões a respeito do marco legal das entidades sem finalidade econômica no país. Dentre as proposições apresentadas, destaca-se a Proposta XXVI, que institui a necessidade de:

definir um modelo jurídico mais adequado para o desenvolvimento de atividades produtivas coletivas e solidárias por grupos e trabalhadores/as, que hoje se situam em um campo nebuloso entre duas institucionalidades jurídicas (associações e cooperativas). Esse debate não pode se dar de forma fragmentada, tendo em vista que a forma constitutiva desses empreendimentos econômicos solidários é basicamente associativa (54\%), seguida por grupos informais (33\%) e por cooperativas (11\%).

1 Fonte: http://www.abong.org.br/. Acessado em 20/05/2009. 
Assim, em face do seu hibridismo, e levando em conta o entendimento atualmente existente por representantes do movimento e pelos instituidores das políticas públicas de fomento a economia solidária, o que se percebe é que há uma preocupação muito mais valorativa que formalista no momento da sua classificação.

Para considerar a organização como empreendimento de economia solidária, não se leva em conta a sua forma de Constituição, mas sim o respeito aos princípios e práticas ${ }^{2}$ da economia solidária. Desse modo, percebe-se que a natureza jurídica não é um fato definidor e seletivo do que seja ou não empreendimento econômico solidário.

\section{AS ORGANIZAÇÕES INFORMAIS}

Tecendo uma abordagem antropológica, as organizações informais podem ser denominadas grupos coletivos capazes de estabelecer relações interpessoais reguladas por mecanismos não contratuais (por meio de acordos tácitos), baseados na confiança, formulados a partir de uma estratégia simbólica de desenvolvimento (COHEN, 1978). Este fenômeno de fato acontece com os empreendimentos econômicos solidários.

Para Cohen (1978), esses agrupamentos ou organizações "invisíveis" que passam por elaborados processos de metamorfose cultural transitam de uma estratégia simbólica para outra em razão das mudanças em suas circunstâncias políticas e socioeconômicas. Ainda que originalmente individualizado, o símbolo, quando absorvido pelo grupo, torna-se coletivo e componente da identidade social. E não é possível negar a existência dessas relações não contratuais na tessitura da vida social.

Assim, em que pese não serem reconhecidos como sujeitos de direito, as organizações informais existentes no movimento de economia solidária não só existem como estabelecem inúmeras relações por meio de mecanismos não contratuais, com objetivo de atender a sua finalidade.

Inúmeras organizações, apesar de não formalizadas, possuem estatutos e atas não registrados, capazes de definir regras de conduta para seus membros. Símbolos são instituídos e aspirados pelo grupo e acabam por fazer parte da componente identitária da organização.

Cohen ainda complementa que negócios são a todo instante estabelecidos por mecanismos não contratuais. Transações são diariamente concluídas sem uso de documentos, contratos, exclusivamente por meios, regras, práticas costumeiras, informais "observadas no interior de um grupo social específico". Assim, percebemos que os

2 Conforme projeto de lei que dispõe sobre a criação da Política Estadual de Fomento à Economia Solidária no Estado da Bahia, são consideradas práticas da Economia Solidária: autonomia institucional; democratização dos processos decisórios; exercício de atividade econômica em organização de padrão comunitário e solidário de estruturação e relações sociais; comércio justo; consumo consciente; finanças solidárias; agregação de finalidades econômica e social. 
comportamentos simbólicos não são exclusivos das sociedades primitivas. Redescobrese na sociedade contemporânea a presença desses comportamentos marcados pela presença objetiva e coletiva de suas manifestações.

Sucintamente estabelecidas as considerações antropológicas acerca dos empreendimentos econômicos solidários informais, delinearemos agora sua perspectiva sob o ponto de vista da análise jurídica.

Para o direito, essas organizações informais são irregulares, existentes de fato, mas não de direito. É importante frisar que essa informalidade ocasiona reflexos danosos aos Empreendimentos Solidários tendo em vista que dificultam sua acessibilidade a políticas públicas.

Conforme cita o documento base da II Conferência Nacional de Economia Solidária - CONAES, o Sistema de Informações em Economia Solidária (SIES) identificou que cerca de um terço (1/3) dos empreendimentos econômicos solidários são informais e $10 \%$ se organizam como cooperativas.

O documento ainda alude que: "Nas áreas urbanas, a situação é ainda mais grave com a informalidade atingindo dois terços (2/3) dessas organizações econômicas solidárias."

A respeito dos dados estatísticos temos a seguinte configuração no que tange às formas de organização dos empreendimentos econômicos solidários na Bahia ${ }^{3}$ :

\begin{tabular}{lr}
\hline \multicolumn{1}{c|}{ FORMAS DE ORGANIZAÇÃO } & QUANTIDADE \\
\hline Associação & 1.131 \\
\hline Grupo Informal & 318 \\
\hline Cooperativa & 143 \\
\hline Sociedade mercantil de capital e indústria & 10 \\
\hline Outra & 6 \\
\hline Sociedade mercantil por cotas de responsabilidade limitada & 3 \\
\hline Total & 1.611 \\
\hline
\end{tabular}

Fonte: MTE/SENAES/SIES (2007)

A partir dos dados acima apresentados, importante observar que 19,74\% dos empreendimentos econômicos solidários autodeclaram-se como informais, 70,20\% como organizações associativas e $6,20 \%$ como cooperativas.

Entretanto, conforme verificaremos, isso não significa dizer que realmente possuem este modelo-jurídico organizacional. Muitas organizações que se reconhecem pelos

3 Fonte: SIES - Instituído pelo Ministério do Trabalho e Emprego, mediante Portaria n. ${ }^{\circ} 30$, de 20 de março de 2006, sob responsabilidade da Secretaria Nacional de Economia Solidária. Pesquisado no endereço eletrônico: http://www.mte.gov.br/ecosolidaria/sies.asp. Acessado em: 19/07/2010. 
modelos acima epigrafados, não possuem CNPJ nem registros jurídicos capazes de lhes garantir esta formatação jurídica.

Os dados regionais não são muito diferentes (Região Nordeste):

\begin{tabular}{l|r}
\hline & \\
\hline Associação & 6.153 \\
\hline Grupo informal & 2.640 \\
\hline Cooperativa & 586 \\
\hline Outras formas de organização & 70 \\
\hline Total & 9.449 \\
\hline
\end{tabular}

Fonte: MTE/SENAES/SIES (2007)

A tabela abaixo relaciona o número de empreendimentos com CNPJ - Cadastro Nacional de Pessoa Jurídica por região:

\begin{tabular}{l|r}
\hline & \\
\hline Região Norte & 1.420 \\
\hline Região Nordeste & 5.467 \\
\hline Região Sudeste & 1.424 \\
\hline Região Sul & 1.466 \\
\hline Região Centro-Oeste & 1.125 \\
\hline Cooperativa & 586 \\
\hline Total & 10.902 \\
\hline
\end{tabular}

Fonte: MTE/SENAES/SIES (2007)

Conforme aludido, relevante observar que em que pese 6.153 organizações da Região Nordeste se autodeclararem como associações, apenas 5.467 empreendimentos afirmam possuir Cadastro Nacional de Pessoa Jurídica - CNPJ. Observe que essas organizações não se consideram informais, mas sim pertencentes ao modelo jurídico associativo. Tal fato ocorre, pois conforme mencionado, inúmeras organizações reconhecem-se como cooperativas e associações; entretanto, para o direito mantêm-se informais.

Mas, o que estaria levando as referidas organizações a permanecerem informais?

Inúmeras são as justificativas para permanência na informalidade. Como dissemos, no movimento econômico solidário há uma preocupação maior com a substância do que com a forma, e, em razão disso, alguns empreendimentos não percebem a importância e necessidade da Constituição formal.

Muitos grupos não conseguem assumir o custo necessário para a legalização do empreendimento. Alguns empreendimentos ainda justificam que não se constituirão 
enquanto não houver um modelo jurídico organizacional apropriado, tendo em vista que aguardam a aprovação da Política Estadual de Economia Solidária. Há ainda empreendimentos que não se constituem sob a justificativa de não possuírem vontade e nem interesse em se formalizar. Outros relatam que desejam constituir-se como cooperativa (já que precisam praticar atividade econômica não lucrativa), mas não possuem a quantidade mínima suficiente de membros ${ }^{4}$ para formalizar-se utilizando modelo cooperativo. Muitas são as justificativas para permanência como informais.

Importante dizer que a Constituição formal gera obrigações reais, imprescindível de serem cumpridas - fato este que assusta muitos empreendimentos. Muitos deles, não passaram por uma maturação suficiente para formalizar-se. Alguns inexperientes, precipitadamente, formalizam-se e deixam de legado a carregada experiência de não conseguir autossustentar-se. Esta indelével e negativa marca acaba servindo como paradigma para outras, que percebendo a dificuldade enfrentada pelo grupo não maturado, resolve de maneira preconceituosa não se formalizar jamais.

Todas as respostas acima descritas foram relatadas por membros desses empreendimentos em atendimentos realizados pela instrutoria jurídica do Centro Público de Economia Solidária do Estado da Bahia ${ }^{5}$.

O Centro Público de Economia Solidária foi criado pela Superintendência de Economia Solidária - SESOL, vinculado à Secretaria do Trabalho, Emprego, Renda e Esporte - SETRE, como um espaço multifuncional capaz de prestar serviços de assistência técnica, formação e treinamento, oferta de crédito para as cooperativas e associações de produtores, aperfeiçoamento das técnicas produtivas, normatização, padronização, técnicas de comercialização e promoção do acesso às tecnologias de comunicação.

Importante relatar a forma que o documento base da II Conferência Nacional de Economia Solidária - CONAES versa a respeito do tema:

Não é coincidência o fato de que os empreendimentos econômicos solidários mais pobres em geral são informais, tendo enormes dificuldades de acesso às políticas públicas e ao crédito e de superar as barreiras econômicas e sociais para viabilizar essas iniciativas e gerar trabalho digno e renda para seus associados. De fato, as barreiras jurídicas, administrativas, fiscais e tributárias tornam muito difícil registrar e manter uma cooperativa para quem não pode pagar as despesas que são exigidas. Tais dificuldades existem desde o momento de registro nas juntas comerciais, nas receitas municipais, estaduais e federal e, posteriormente, para manter em

4 Segundo a Lei n. ${ }^{\circ} 5.764 / 71$, o número mínimo de sócios para constituir uma cooperativa é de 20 (vinte) pessoas. Contudo, lei geral posterior n. ${ }^{0} 10.406 / 2002$, em seu art. n. ${ }^{\circ} 1.094$, definiu como característica da cooperativa o "concurso de sócios em número mínimo necessário a compor a administração da sociedade". Não houve determinação expressa quanto ao número mínimo necessário capaz de administrar uma sociedade cooperativa.

5 A autora do presente artigo foi instrutora jurídica do Centro Público de Economia Solidária do Estado da Bahia, vinculado à Secretaria do Trabalho, Emprego, Renda e Esporte (SETRE). Participou da construção da minuta do projeto de lei que dispõe sobre a criação da Política Estadual de Fomento à Economia Solidária no Estado da Bahia e do Conselho Estadual de Economia Solidária. 
funcionamento a organização. Trata-se de uma forma de exclusão legal, que se nutre da exclusão social, econômica e cultural. Como contraponto é preciso garantir a isenção das taxas de registro e a desburocratização para assegurar o acesso desses empreendimentos à formalidade.

Em verdade, este não será o foco do nosso artigo. Não procuraremos explicar qual dos motivos é o mais plausível, nem qual o mais reincidente. $\mathrm{O}$ que temos a dizer a respeito da temática é que as organizações informais, embora existam de fato, são invisíveis para o direito. Possuem dificuldades, portanto, para beneficiar-se de políticas públicas para a sua expansão e desenvolvimento, tendo em vista que as sociedades em comum não são objeto de políticas públicas.

O que vemos é um conflito jurídico instalado e uma verdadeira incompreensão da sociedade a respeito do que propriamente seriam estes empreendimentos.

Assim, grande é a dificuldade de o Estado reconhecer o pleito destas organizações "invisíveis", marcada inclusive pela dificuldade na institucionalização dos empreendimentos como sujeitos de direitos diferentes dos atualmente constituídos.

\section{OUTROS ATORES NÃO INSTITUCIONALIZADOS}

É importante destacarmos que no movimento da economia solidária o empreendimento econômico solidário não é o único ator não institucionalizado. Redes de cooperação solidária têm-se formado estabelecendo conexões entre empreendimentos, promovendo a ajuda mútua dessas organizações, independente da formalização desses sujeitos.

Conforme previsto na Minuta do Projeto de lei da Política Estadual de Fomento à Economia Solidária do Estado da Bahia - PEFES', "Rede de Empreendimentos de Economia Solidária é aglutinação de Empreendimentos de Economia Solidária que, conservando autonomia organizacional, unem-se para alcançar objetivos comuns." Importante salientar que, na prática, a própria rede é uma relação sem formalidades.

As trocas sociais simbólicas também denominadas "clube de trocas" ou "trocas solidárias" também não se preocupam com a formalização. Elas adotam um mecanismo de troca recíproca, em que o sujeito contribui com bem ou serviço, recebe determinada quantidade de moeda social (também informal) em contrapartida pelo que contribuiu, e em seguida, por meio da moeda, compra novos produtos de outros empreendimentos solidários. Nesse instante, surge a figura do "prossumidor", pessoa que ao mesmo tempo é consumidora e produtora de bens e serviços.

A feira de economia solidária, realizada todos os anos na Bahia, é momento capaz de interconectar os empreendimentos econômicos solidários baianos em um só

6 Art. 15. Para efeito desta lei, Rede de Empreendimentos de Economia Solidária é aglutinação de Empreendimentos de Economia Solidária que, conservando autonomia organizacional, unem-se para alcançar objetivos comuns. 
lugar, e nessa ocasião, não há qualquer preocupação com a possibilidade de se ter empreendimentos informais participando das comercializações e das atividades. Não há, portanto, necessidade de comprovar formalização para habilitar-se como empreendimento beneficiário desta ação.

As experiências vividas pelos bancos comunitários também guardam esse afrouxamento nas relações. Os bancos comunitários são organizações responsáveis por oferecer serviços financeiros de natureza comunitária (microcrédito) à população de baixa renda mediante a circulação de moeda social informal. A coordenação do banco e a gestão dos recursos são em geral efetuadas por uma organização comunitária. A concessão de crédito e a cobrança dos empréstimos são realizadas por meio de mecanismos não contratuais, baseadas nas relações de vizinhança, confiança e domesticidade, permitindo que o controle seja mais social que econômico.

\section{CONCLUSÃO}

Em que pese não se tratar de atores recentes, todo o contexto apresentado alhures a respeito da realidade vivida pelos atores da economia solidária apenas hodiernamente passou a ser analisado no Brasil, especialmente no que se refere aos Empreendimentos de Economia Solidária. Por essa razão, ainda não foram instituídos padrões jurídicos para amparar as organizações econômico solidárias.

Por todo o Brasil o movimento de economia solidária luta pela construção de um marco jurídico capaz de dar segurança jurídica às formas coletivas acima apresentadas, robustecida pelas resoluções da Conferência Nacional de Economia Solidária - CONAES (2010) e pela criação do Comitê Temático do Marco Jurídico da Economia Solidária, no âmbito do Conselho Nacional de Economia Solidária - CNES. Inúmeros documentos a respeito do tema trazem como um dos principais objetivos das políticas públicas de economia solidária a necessidade de instituição do marco legal da economia solidária.

O mote da II Conferência Nacional da Economia Solidária - CONAES (2010) refere-se a uma questão fundamental para fortalecer e viabilizar a economia solidária no Brasil: "o direito às formas de organização econômica baseadas no trabalho associado, na propriedade coletiva, na cooperação e na autogestão, reafirmando a economia solidária como estratégia e política de desenvolvimento" (BRASIL, 2010, p. 3).

Conforme abordado no início deste trabalho, Geertz (2009) propõe que o direito una-se a outras "grandes formações culturais da vida humana - a moral, a arte, a tecnologia, a ciência, a religião, a divisão do trabalho, a história" e assevera que tais categorias não são mais unitárias, definidas, nem mais universais que o direito. $O$ Direito se propõe a estudar as regras de convivência entre os sujeitos.

A normatização das relações humanas, ou seja, a definição de padrões mínimos de conduta é algo que apenas se alcança depois de verificada forte evolução no contexto empírico. Desse modo, apenas após fase experimental cria-se o direito. 
Conforme demonstrado pelo Sistema Nacional de Informações em Economia Solidária - SIES, diversas são as formas adotadas pelos atores sociais. A variabilidade de modelos regulares adotados, bem como - principalmente - a alta incidência de organizações informais, demonstra que a sociedade contemporânea precisa progredir no sentido de promover a compreensão desses atores sociais solidários.

E esse progresso precisa emergir com urgência, tendo em vista que em razão da ausência de um modelo jurídico próprio, capaz de se determinar o que são empreendimentos econômicos solidários, os grupos informais enfrentam grande dificuldade no que se refere ao acesso às políticas públicas.

\section{REFERÊNCIAS}

ANTUNES, Ricardo. Dimensão da precarização estrutural do trabalho. In: A perda da razão social do trabalho: terceirização e precarização. DRUCK, Graça; FRANCO, Tânia (Org.). São Paulo: Boitempo, 2007, p. 13-22.

Associação Brasileira de ONGs - ABONG. Uma regulação de acesso e utilização de recursos públicos para organizações sem fins lucrativos no Brasil. Rio de Janeiro. 2008. Disponível em: < http//www. abong.org.br $>$.

Associação Brasileira de ONGs - ABONG. Manual de administração jurídica, contábil e financeira para organizações não governamentais. São Paulo: Peirópolis, 2003.

Bahia Análise de Dados. Economia Solidária. Vol. 12, n. 1, Salvador: junho de 2002.

BARBOSA, Rosângela Nair de Carvalho. A economia solidária como política pública: uma tendência de geração de trabalho e renda e ressignificação do trabalho no Brasil. São Paulo: Cortez, 2007.

BAUMAN, Zygmunt. Aprendendo a pensar com a sociologia. Rio de Janeiro. Editora Zahar, 1925. Ed. 2010.

BOURDIEU, Pierre. O Poder Simbólico. Rio de Janeiro, Bertrand Brasil, 2003.

BRASIL. II Conferência Nacional de Economia Solidária. Documento Base. BRASÍLIA: SENAES/ MTE, 2010.

BUCCI, Maria Paula Dallari. O conceito de Política pública em direito. In: BUCCI, Maria Paula Dallari (Org.). Políticas Públicas: reflexões sobre o conceito jurídico. São Paulo: Saraiva, 2006.

CATTANI, David. (Org.). A outra economia. Porto Alegre: Veraz Editores, 2003.

COHEN, Abner. O homem bidimensional: A antropologia do poder e do simbolismo em sociedades complexas. Rio de Janeiro: Zahar Editores, 1978.

DIAS, Gabriela da Luz; MATOS, Igor Loureiro de. Módulo Jurídico para empreendimentos de economia solidária. Salvador, Netcoop, 2010.

FERRAZ JR., Tércio Sampaio. Introdução ao Estudo do Direito: técnica, decisão, dominação. 3. ed. SP: Atlas, 2001.

GAIGER, Luiz. I. (Org.). Sentidos e experiências da economia solidária no Brasil. Porto Alegre: Editora da UFRGS, 2004. 
GEERTZ, Clifford. O saber local: novos ensaios em antropologia interpretativa. Rio de Janeiro: Editora Vozes, 2009.

LIMA, Jacob. As artimanhas da flexibilização: o trabalho terceirizado em cooperativas de produção. São Paulo: Terceira Margem, 2002.

MANCE, E. Redes de colaboração solidária. Petrópolis: Vozes, 2002.

SANTOS, Boaventura de Sousa (Org.). Produzir para viver: os caminhos da produção não capitalista. Rio de Janeiro: Civilização Brasileira, 2002.

SARMENTO, Daniel. Direitos Fundamentais e Relações Privadas. Rio de Janeiro: Lumen Juris, 2004.

SILVA, Maria Ozanira da Silva e; YAZBEK, Maria Carmelita (Orgs.). Políticas públicas de trabalho e renda no Brasil contemporâneo. São Paulo: Cortez; São Luís: FAPEMA, 2006.

SINGER, Paul. Introdução à Economia Solidária. SP: Editora Fundação Perseu Abramo, 2002.

SINGER, Paul. A recente ressurreição da economia solidária no Brasil. In: SANTOS, B. S. Produzir para viver: os caminhos da produção não capitalista. Rio de Janeiro: Civilização Brasileira, 2002a, p. 81-130.

SINGER, Paul, SOUZA, André R. A Economia Solidária no Brasil: A autogestão como resposta ao desemprego. São Paulo: Contexto, 2003.

SZAZI, Eduardo. Terceiro Setor: temas polêmicos. v. 1 e 2. São Paulo: Fundação Peirópolis, 2004.

PEREIRA, Caio Maio da Silva, Instituições de Direito Civil, Rio de Janeiro: Forense, 2001, v. 1, p.186.

RAZETO, Luis M. (*) Artigo publicado na revista Persona y Sociedad, Volumen XIII, No 2 Agosto de 1999, Santiago de Chile.

RAZETO, Luis M. Economia de solidaridad y mercado democrático. Santiago de Chile: PET, 1985, v.2. 